\title{
Intra-renal arterio-venous fistula with associated carcinoma of the kidney
}

\author{
W. J. MacLennan \\ M.B., Ch.B., M.R.C.P.(Glasg.), M.R.C.P.(Lond.) \\ Lecturer, Department of Materia Medica and Therapeutics, \\ University of Glasgow, Glasgow, W.2
}

\author{
R. ScOTT* \\ M.B., Ch.B., F.R.C.S.(Glasg.), F.R.C.S.(Edin.) \\ Registrar, Department of Surgery, \\ Stobhill General Hospital, Glasgow, N.1
}

The investigation of the renal vasculature by angiography has resulted in the demonstration of arterial and venous anomalies causing hypertension which are remediable by surgery. The most common lesion treated is renal artery stenosis (de Wardener, 1961) but an increased incidence of intra-renal arterio-venous fistulae has been noted in recent years. This is a much rarer cause of hypertension.

\section{Case report}

The patient, Mrs J.S., aged 54, was first admitted to Stobhill General Hospital on 17 August 1965 . Five years previously she had been investigated elsewhere because of haematuria and hypertension. A diagnosis of chronic pyelonephritis affecting the left kidney was made on the evidence of the intravenous pyelogram. She had been taking methyldopa, $500 \mathrm{mg}$ t.i.d. since that time.

Six weeks prior to her admission to Stobhill she had suddenly developed a bitemporal headache associated with a transient loss of vision. The headache had persisted since then, and had occasionally been associated with vomiting.

On examination the only abnormality was a gross lumbar kyphoscoliosis. The pulse was regular, $185 / 100 \mathrm{mmHg}$. The apex beat was 5 in. from the midline in the fifth left interspace and was heaving in character. The fundi showed grade 2 hypertensive changes. These findings were associated with the presence of a harsh continuous murmur over the left renal angle. No neurological abnormalities could be detected.

The possibility of a mild subarachnoid haemorrhage was considered, but skull X-ray, CSF analysis, electro-encephalography and bilateral

\footnotetext{
*Present address: Senior Registrar, Department of Urology, The Royal Infirmary, Glasgow, C.4.
}

carotid and vertebral artery angiography all failed to demonstrate any intracranial lesion. An ECG and chest $\mathrm{X}$-ray both demonstrated the presence of left ventricular hypertrophy.

Attention was also directed to the signs elicited over the left loin. Urinalysis was negative. The urine was sterile and the serum urea was $26 \mathrm{mg} /$ $100 \mathrm{ml}$. An IVP showed inadequate filling of the left renal pelvis and elongation of its upper major calyx which suggested the possibility of a spaceoccupying lesion. A left retrograde pyelogram confirmed these findings (Fig. 1). An isotope renogram indicated impairment of left renal function (Fig. 2). Lumbar aortography failed to demonstrate the left renal artery but revealed the presence of a large group of dilated vessels in the upper two-thirds of the left kidney (Fig. 3). These findings suggested that the subject's hypertension could be due to an intra-renal arteriovenous fistula, and therefore a laparotomy was arranged.

Operation. On 18 October 1965 the left kidney was explored through a lumbar approach and a standard nephrectomy performed. It was noted that the left upper pole was adherent to the capsule. A carcinoma was found involving the upper one-third of the kidney substance. The peri-renal veins were normal. An upper polar vessel with a globular aneurysm $5 \mathrm{~cm}$ from the kidney substance was also demonstrated. Similarly a lower polar artery was found; this vessel was large and bifurcated at the hilum. Following this procedure the patient made an uninterrupted recovery and when seen at the outpatient department on 10 December 1965 her blood pressure had fallen to $120 / 70 \mathrm{mmHg}$ without the use of hypotensive agents. This improvement has been sustained and when last seen on 15 March 1967 she had no symptoms and her blood pressure was $135 / 80 \mathrm{mmHg}$. There was no evidence of any secondary spread of tumour. 

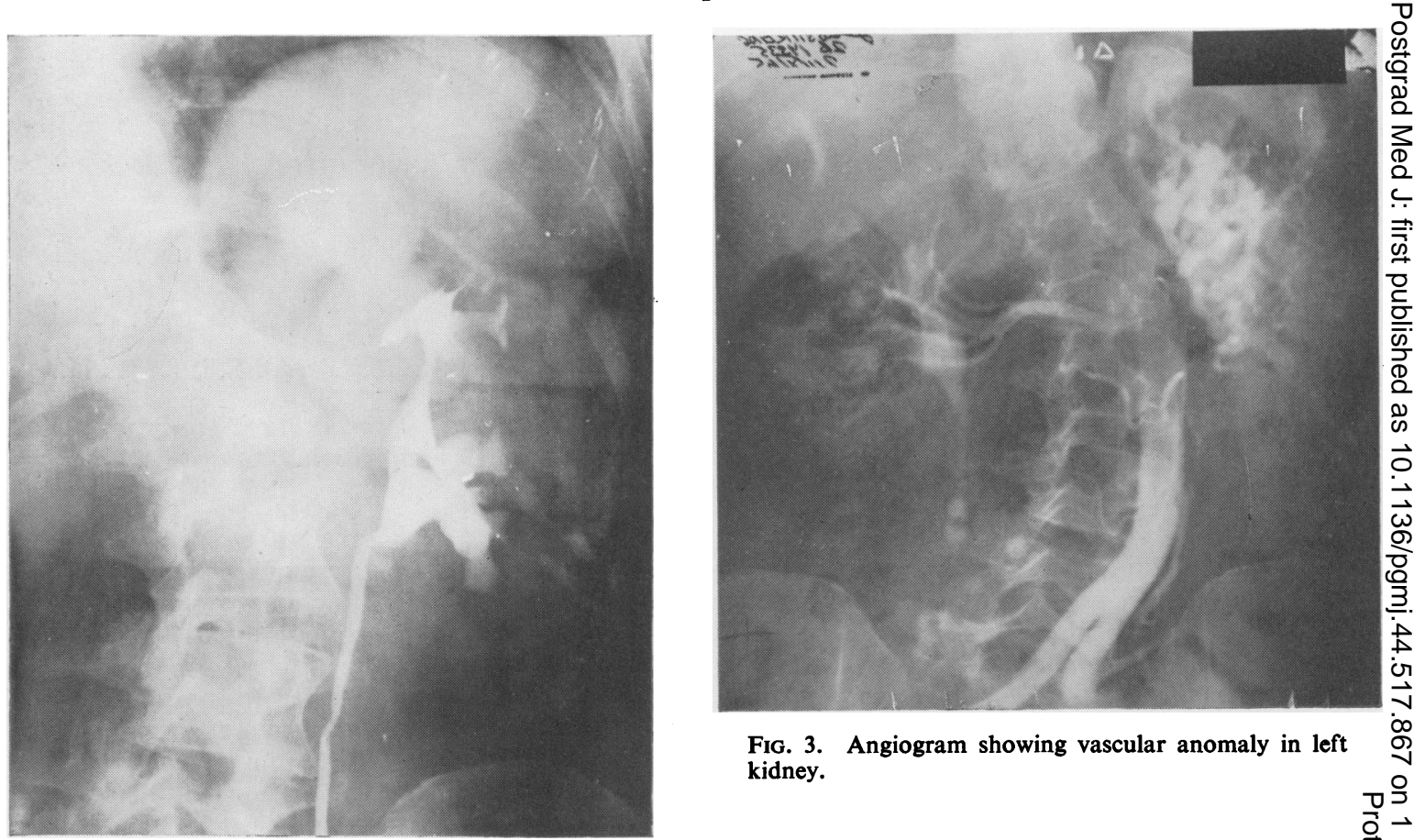

Fig. 1. Retrograde pyelogram confirming IVP findings in left kidney.

Fig. 3. Angiogram showing vascular anomaly in left kidney.

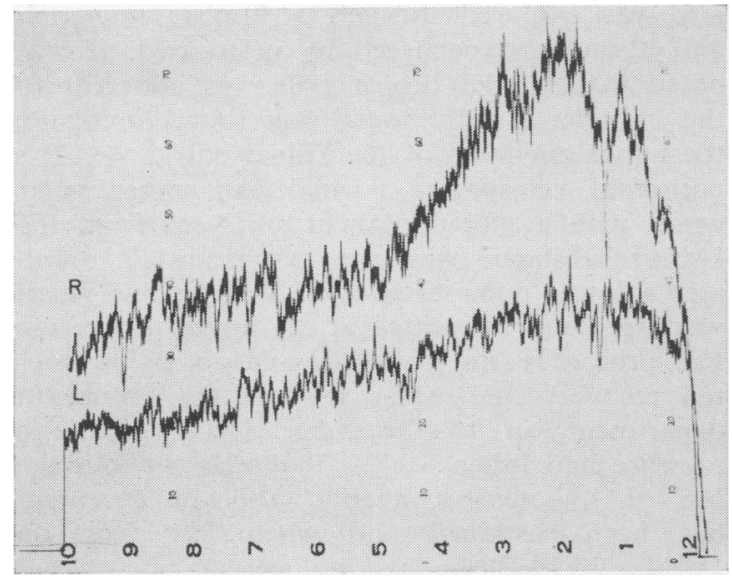

FIG. 2. Isotope renogram showing impaired left renal function.

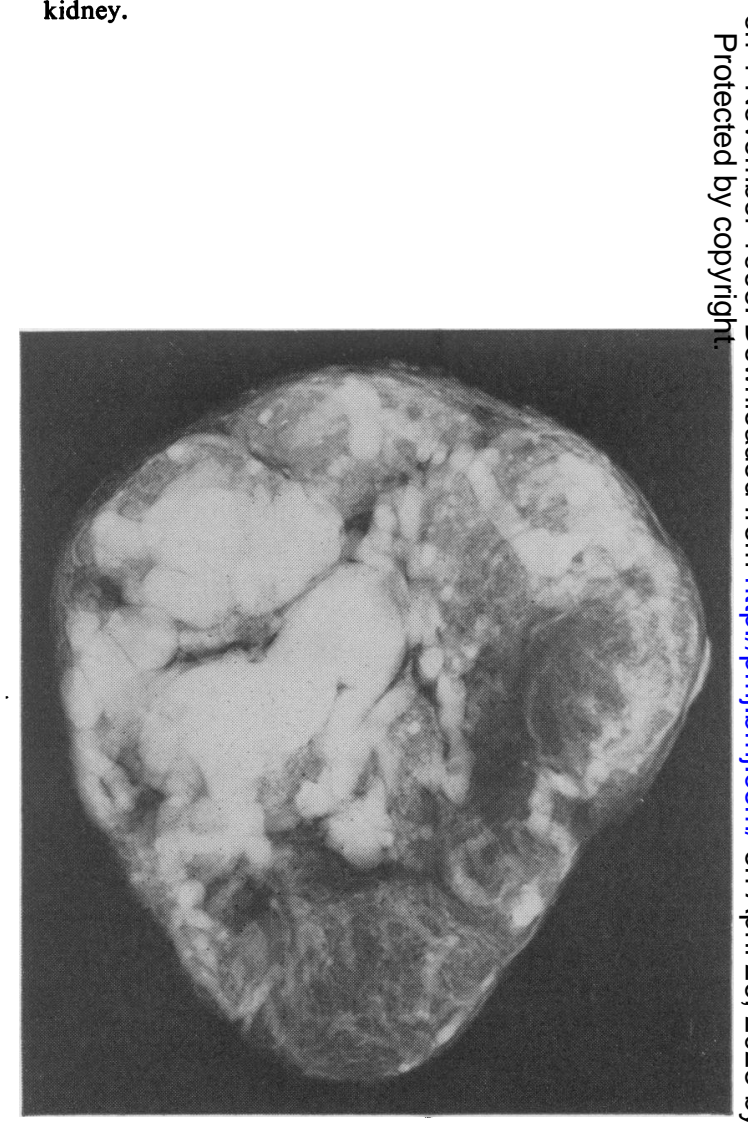

Fig. 4. Radiograph of tumour injected with radioopaque medium.

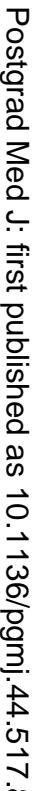

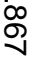


The ECG had returned to normal and her serum urea was $53 \mathrm{mg} / 100 \mathrm{ml}$.

\section{Pathology}

The excised specimen was irrigated with saline through the main renal artery until the fluid issuing from the renal vein became clear. Following this $2 \mathrm{ml}$ of a mixture of $35 \%$ barium sulphate and $15 \%$ gelatin was injected. A series of standard and stereoscopic radiographs were taken.

These showed the central renal artery communicating with dilated vascular spaces in the upper half of the kidney (Fig. 4).

Naked eye, the cut section of the kidney revealed a rounded mass of tumour tissue involving the upper-third of the kidney. The edge of the tumour was well delineated but not encapsulated. There was no tumour tissue in the renal vein. Histology (Fig. 5) showed the tumour to be a clear-cell carcinoma containing large and small vascular lacunae.

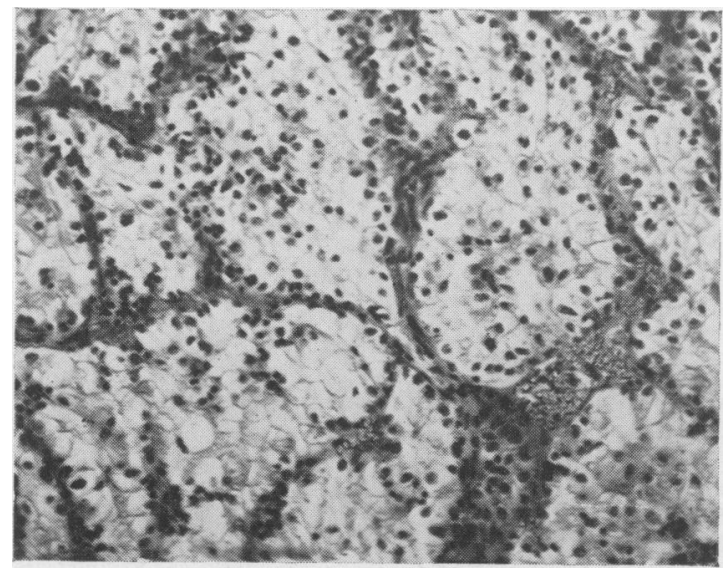

FIg. 5. High power field of clear cell adenoma. H \& E, $\times 8$.

\section{Discussion}

An intra-renal arterio-venus fistula was first recorded in 1923 (Varela, 1923) and up to 1947 only three cases had been added to the world literature (Chisolm, 1966). Since then the condition, though rare, has been recorded with increasing frequency. Palmer \& Connelly (1966) traced forty-four cases in the literature and noted that $50 \%$ of these had been recorded in the previous 3 years.

This has probably been a result of the increased use of renal angiography as a diagnostic procedure (Riley, 1965). Love, Moncada \&
Lescher (1965) classify these lesions as being: (a) congenital, and (b) acquired. The latter may result from: (1) trauma, (2) stump fistula, and (3) renal carcinoma. The congenital fistula probably develops when a pre-existing intra-renal aneurysm ruptures into the renal vein. Traumatic causes include penetrating or subcutaneous injury (Love et al., 1965), renal biopsy (Riley, 1965), partial nephrectomy (Snodgrass \& Robertson, 1964) and nephrolithotomy (Boijsen \& Kohler, 1962). Stump fistula is a recognized complication of ligation of the renal vascular pedicle. Boijsen \& Kohler (1962) argue that the fistula associated with renal carcinoma should be considered as a separate entity. Rarer reports of the condition include an arterio-venous fistula in a polycystic kidney (Chisholm, 1966).

Diagnosis of the condition is based upon the presence of a continuous bruit over the affected kidney, and upon characteristic abnormalities in the renal angiogram. These consist of large dilated vessels in the kidney, and early filling of the renal vein and inferior vena cava (Love et al., 1965). Intravenous and retrograde pyelograms may demonstrate filling defects in the renal pelvis. An isotope renogram may show flattening of the normal pattern over the affected kidney (Maldanado, Sheps \& Bernatz, 1964). Such changes are not specific for renal arteriovenous fistula.

A renal arterio-venous fistula has several effects upon the circulatory system. The presence of a shunt in the peripheral circulation produces a decrease in systolic and diastolic blood pressures, an increased pulse rate, a raised central venous pressure and an increase in cardiac output. These circulatory changes are, however, modified by the fact that when a fistula is sited in the kidney there is a reduction in blood flow to the parenchyma producing a Goldblatt phenomenon with hypertension. These changes result in left ventricular hypertrophy and subsequent failure (Long, Javid \& Julian, 1964).

Nephrectomy is the standard treatment, and this has resulted in the return to a normal blood pressure in $80 \%$ of cases, with a significant reduction in the medication necessary for its control in the remainder. Palmer \& Connelly (1966) have described a case where the fistula was excised using selective renal hypothermia with survival of the kidney.

The case described here presented with symptoms suggestive of a minor subarachnoid haemorrhage. This was not confirmed. The features suggesting a renal vascular anomaly were the association of hypertension and mild left ventricular hypertrophy with a bruit over the left renal 
angle. Intravenous and retrograde pyelography showed a filling defect in the renal pelvis, and the isotope renogram suggested impaired renal function. A definitive diagnosis was only made after renal angiography.

It is thought in this case that the carcinoma must have caused the haematuria previously investigated and probably at that stage caused radiological changes which were mistaken as being caused by chronic pyelonephritis. It is of interest to note that there has been no evidence of any secondary spread from this lesion.

\section{Acknowledgments}

We wish to thank Dr W. F. M. Fulton and Mr W. Gray for allowing us to publish this case and for their help and advice in the preparation of this paper. We are also indebted to Dr J. W. Dobie of the Pathology Department, Glasgow Royal Infirmary for the radiographs of the tumour specimen.
References

BoIJSEN, E. \& KoHLER, R. (1962) Renal arterio-venous fistulae. Acta radiol. (Stockholm), 57, 435.

Chisolm, G.D. (1966) An Arteriovenous fistula in a polycystic kidney. J. Urol. 96, 854.

LONG, L., JAVID, H. \& JuliaN, O.C. Arteriovenous fistula of renal vessels. Ann. Surg. 160, 239.

Love, L., Moncada, R. \& Lescher, A.J. (1965) Renal arteriovenous fistulae. Amer. J. Roentgenol. 95, 364.

Maldanado, J.E., Sheps, S.G. \& Bernatz, P.E. (1964) Renal arteriovenous fistula. A reversible cause of hypertension and heart failure. Amer. J. Med. 37, 499.

PAlmer, J.M. \& ConNelly, J.E. (1966) Intra-renal arteriovenous fistulae; surgical excision under selective renal hypothermia with kidney survival. J. Urol. 96, 599.

RILEY, J.N. (1965) Renal arteriovenous fistula; a complication of percutaneous renal biopsy. J. Urol. 93, 335.

SNOdgrass, W.T. \& Robertson, M.J. (1964) Intra-renal arteriovenous fistula; a complication of partial nephrectomy. J. Urol. 91, 135.

VARela, M.E. (1923) Aneurisma arteriovenoso de los vacos renales y asistolia consecutiva. Rev. méd. lat. amer. 14, 3244.

De Wardener, H.E. (1961) The Kidney, p. 100. Churchill, London.

\title{
A death from tetracycline
}

\author{
Gillian C. HaNSON \\ M.B., M.R.C.P. \\ Consultant Physician, \\ Whipps Cross Hospital, Leytonstone, London, E.11
}

\section{Case report}

A female of 43 years was admitted with a history of vomiting for 5 days and onset of severe abdominal pain $24 \mathrm{hr}$ prior to admission. A duodenal ulcer had been diagnosed 1 year previously, and since then she had suffered from epigastric discomfort which was relieved by alkalis.

On admission she was shocked, the blood pressure being unrecordable. A diagnosis was made of gastro-intestinal perforation. Over the next few hours, following intravenous fluid therapy, her blood pressure rose to $110 / 70 \mathrm{mmHg}$. Laparotomy was performed $6 \mathrm{hr}$ after admission when her general condition had improved. A large perforation was found in the first part of the duodenum, and 1.5 litres of bile-stained fluid were aspirated from the peritoneal cavity. The perforation was closed. The liver, gallbladder and pancreas appeared normal.

Post-operatively the patient's condition improved, her blood pressure rose to $140 / 90$; she was apyrexial and gastric aspiration over the ensuing $24 \mathrm{hr}$ was only $620 \mathrm{ml}$.

Tetracycline was commenced at the time of operation at a rate of $500 \mathrm{mg}$ intravenously, 8 hourly; this was changed to $2.0 \mathrm{~g}$ orally daily on the 4th and 5th post-operative days (see Fig. 1).

The patient was oliguric over the first $48 \mathrm{hr}$ post-operatively but subsequently the urine output was adequate (see Fig. 1). Five days postoperatively the patient became drowsy and was noted to be slightly jaundiced with a morbilliform irritating rash over the whole of the body. Serum bilirubin at this time was $6.1 \mathrm{mg} / 100 \mathrm{ml}$, urinary urobilinogen was increased and bilirubin was also present. The rash subsided on antihistamine therapy over the next few days and the jaundice faded. Six days after the operation she developed severe diarrhoea and, in view of the history of jaundice and skin rash, tetracycline was cancelled.

In spite of a good urine output with no rise 